\title{
Titanium as a Potential Addition for High-Capacity Hydrogen Storage Medium
}

\author{
Filippo Zuliani, ${ }^{1,2}$ Leonardo Bernasconi, ${ }^{1,3}$ and Evert Jan Baerends ${ }^{1,4,5}$ \\ ${ }^{1}$ Theoretische Chemie, Vrije Universiteit Amsterdam, De Boelelaan 1083, 1081 HV Amsterdam, The Netherlands \\ ${ }^{2}$ Tata Steel Research, Development and Technology, Tata Steel Europe, 1970 CA Ijmuidem, The Netherlands \\ ${ }^{3}$ Science and Technology Facilities Council Rutherford Appleton Laboratory, Harwell Science and Innovation Campus, \\ Didcot, Oxfordshire OX11 0QX, UK \\ ${ }^{4}$ WCU Program, Department of Chemistry, Pohang University of Science and Technology, Pohang, Republic of Korea \\ ${ }^{5}$ Chemistry Department, Faculty of Science, King Abdulaziz University, Jeddah 21589, Saudi Arabia
}

Correspondence should be addressed to Filippo Zuliani, fzuliani74@gmail.com

Received 7 March 2012; Accepted 1 May 2012

Academic Editor: Won Baek Kim

Copyright ( 2012 Filippo Zuliani et al. This is an open access article distributed under the Creative Commons Attribution License, which permits unrestricted use, distribution, and reproduction in any medium, provided the original work is properly cited.

\begin{abstract}
We study the adsorption of hydrogen molecules on a titanium atom supported by a benzene molecule using generalized gradient corrected Density Functional Theory (DFT). This simple system is found to bear important analogies with titanium adsorption sites in $(8,0)$ titanium-coated single-walled carbon nanotubes (SWNTs) (T. Yildirim and S. Ciraci, 2005) In particular, we show that up to four $\mathrm{H}_{2}$ molecules can coordinate to the metal ion center, with adsorption patterns similar to those observed in TiSWNTs and no more than one molecule dissociating in the process. We analyze in detail the orbital interactions responsible for Ti-benzene binding and for the electron transfer responsible for the $\mathrm{H}_{2}$ dissociation. We find the latter to involve a transition from a triplet to a singlet ground state as the hydrogen molecule approaches the adsorption site, similar to what has been observed in Ti-SWNTs. The total Ti- $\mathrm{H}_{2}$-binding energy for the first dissociative addition is somewhat inferior $(\sim 0.4 \mathrm{eV})$ to the value estimated for adsorption on Ti-SWNTs. We analyze in detail the orbital interactions responsible for the $\mathrm{H}_{2}$ binding.
\end{abstract}

\section{Introduction}

Developing safe, cost-effective, and practical means of storing hydrogen is crucial for the advancement of hydrogen and fuel-cell technologies [1-3]. In this context, titaniumdecorated organic compounds have received attention for their potential use as high-capacity hydrogen storage materials [4-9]. More in specific, studies based on generalized gradient DFT and first-principle molecular dynamics simulations have indicated that a single-titanium atom supported on an insulating $(8,0)$ SWNT can bind up to four hydrogen molecules [10]. Since high titanium coverages on SWNTs are achievable in experimental conditions, these materials could provide means to reach, or even exceed, the minimum hydrogen storage capacity required for technological applications.

Adsorption of one $\mathrm{H}_{2}$ molecule to a titanium site was found to proceed with a vanishing activation energy and to involve interactions between carbon atoms, titanium, and the hydrogen molecule which are essentially short ranged and localized at the absorption site. It was proposed that the mechanism responsible for the $\mathrm{H}_{2}$ bonding involves $\mathrm{d}$ orbitals of the Ti atom, the antibonding $\sigma_{u}$ of a $\mathrm{H}_{2}$ molecule, and $\mathrm{p}$ orbital at carbon sites.

In this paper we present a DFT study that elucidates the catalytic role played by the Ti atom in the dissociation of the $\mathrm{H}_{2}$ molecule and in the bonding mechanism of the $\mathrm{Ti}$ atom and the four hydrogen molecules, characterized as "an unusual combination of chemisorption and physisorption" [10]. According to the results presented here, the same number of hydrogen molecules can be stored in essentially the same configuration introducing a different support for the $\mathrm{Ti}$ catalyst, the benzene molecule. The benzene molecule thus offers a hexagonal ring as support for $\mathrm{Ti}$ which is electronically very similar to the $(8,0)$ SWNT, so that bonding of $\mathrm{H}_{2}$ molecules can be studied in detail using wellestablished molecular energy decomposition techniques and programs [11]. 
The paper is organized as follows. Details about the calculations are given in Section 2. The adsorption and dissociation of a $\mathrm{H}_{2}$ molecule on benzene-supported titanium is analyzed in Section 3.1, and the possible addition patterns for two and four molecule additions are studied in Section 3.3. Our results are briefly summarized in Section 4.

\section{Computational Details}

Calculations have been performed using the Amsterdam Density Functional program (ADF) [12-14]. The molecular orbitals (MOs) were expanded in large uncontracted sets of Slater-type orbitals containing diffuse functions of TZ2P quality. A small frozen core ( 1 s for $\mathrm{C}, 1 \mathrm{~s}-2 \mathrm{p}$ for $\mathrm{Ti}$ ) was used in the present calculations. Equilibrium structures were optimized using analytical gradient techniques, with geometries and energies calculated at the OLYP $[15,16]$ level of theory. Our choice for the functional is motivated by its superior performance for the relative energies of different spin states of various transition-metal complexes in the gas phase, in particular when high-spin states are involved [17-19]. Interactions between $\mathrm{H}_{2}$ molecules and the $\mathrm{C}_{6} \mathrm{H}_{6}$ Ti complexes were analyzed using the molecular fragment method that is a standard tool in energy decomposition methods for interactions between molecules, as detailed in Reference [11]. We use here primarily the description of the orbitals of the overall system expressed as linear combinations of fragment orbitals. The obvious fragments here are Ti, benzene and $\mathrm{H}_{2}$ molecules. The orbitals of these fragments are obtained (in the exact geometry they have in the total system) in separate calculations. These orbitals are then used as basis functions in the overall calculation. This affords an analysis of the overall orbitals in terms of percentages of the contributing fragment orbitals.

\section{Results and Discussion}

3.1. Orbital Interactions and Bonding in $\mathrm{C}_{6} \mathrm{H}_{6}-\mathrm{Ti}$. The structure of the $\mathrm{C}_{6} \mathrm{H}_{6}$-Ti complex has been theoretically [2027] and experimentally [28] studied on the basis of DFT calculations and laser evaporation methods. Experimental evidence indicates the ground state to be a triplet in a planar $\mathrm{C}_{6 v}$ configuration. We show in Figure 1 the orbital interaction diagram of the benzene molecule and the $\mathrm{Ti}$ atom obtained at the OLYP level of theory for the optimized triplet $\mathrm{C}_{6 v}$ configuration. In this analysis, the $\mathrm{C}_{6} \mathrm{H}_{6}-\mathrm{Ti}\left(\mathrm{C}_{6 v}\right)$ compound was divided in two fragments: the isolated $\mathrm{Ti}$ atom and the benzene support, their geometries fixed to the relaxed interacting configuration. From now on, we will take the $x y$-plane as the plane parallel to $\mathrm{C}_{6} \mathrm{H}_{6}$. When interacting with the planar $\mathrm{C}_{6} \mathrm{H}_{6}$, the $3 \mathrm{~d}$ set of the metal atomic orbitals (AOs) are split into three levels of $\mathrm{E}_{2}, \mathrm{~A}_{1}$, and $\mathrm{E}_{1}$ symmetry, the $3 \mathrm{da}_{1}\left(\mathrm{~d}_{z^{2}}\right)$ orbital, two $3 \mathrm{e}_{2}\left(\mathrm{~d}_{x y}\right.$ and Ti- $\left.3 \mathrm{~d}_{x^{2}-y^{2}}\right)$, and two $3 \mathrm{e}_{1}^{*}\left(\mathrm{~d}_{x z}\right.$ and $\left.\mathrm{d}_{y z}\right)$ orbitals, respectively. The important bonding interaction is between the benzene $\pi$ orbitals of $\mathrm{E}_{1}$ symmetry and the Ti- $3 \mathrm{~d}_{x z, y z}$ orbitals, which is understandable considering the relatively large overlap between these favorably oriented orbitals. This leads to significant stabilization of the bonding combination and destabilization of the antibonding combination. There is a weaker interaction between the $\pi$ orbitals of $\mathrm{E}_{2}$ symmetry and the Ti- $3 \mathrm{~d}_{x y}$ and $\mathrm{Ti}-3 \mathrm{~d}_{x^{2}-y^{2}}$ orbitals, which are parallel to the benzene plane and little interaction of the $3 \mathrm{~d}_{z^{2}}$ with the much lower lying $\mathrm{C}_{6} \mathrm{H}_{6}-\pi$ orbital of $\mathrm{A}_{1}$ symmetry. The $3 \mathrm{da}_{1}\left(\mathrm{Ti}-3 \mathrm{~d}_{z^{2}}\right)$ AO is somewhat stabilized by the small hybridization with the $4 \mathrm{~s}$ and $4 \mathrm{p}$ of the same symmetry. The orbital pattern for the d orbitals is reminiscent of the one for sandwich complexes, but a peculiarity of the $\mathrm{C}_{6} \mathrm{H}_{6}$-Ti system is the presence of a low-lying $4 \mathrm{~s}$ orbital, hardly displaced from its atomic position $[26,29]$. This is related to Ti being coordinatively very unsaturated; in highly coordinated (hexa- or penta-coordinated) metal complexes the $4 \mathrm{~s}$ is invariably very much destabilized by the orthogonality requirement on the occupied ligand orbitals.

The four $\mathrm{d}$ electrons of $\mathrm{Ti}$ are available to go into the $\mathrm{C}_{6} \mathrm{H}_{6} \mathrm{Ti}-\mathrm{de}_{2}$ and $-\mathrm{da}_{1}$ orbitals. Because there is only a small gap between these orbitals, the "high-spin" configuration $\left(e_{2}\right)^{3}\left(d_{1}\right)^{1}$ results, leading to a triplet ground state of $E_{2}$ symmetry. This is Jahn-Teller distorted, so that the degeneracy of the $e_{2}$ MO is lifted. Our OLYP calculations predict a triplet- $\mathrm{C}_{2 v}$ configuration as ground state of the $\mathrm{C}_{6} \mathrm{H}_{6}$ Ti compound, with the quintet- $\mathrm{C}_{6 v}\left(\mathrm{e}_{2}\right)^{2}\left(\mathrm{da}_{1}\right)^{1}(4 \mathrm{~s})^{1}$ and triplet- $\mathrm{C}_{6 v}\left(\mathrm{e}_{2}\right)^{3}\left(\mathrm{da}_{1}\right)^{1}(4 \mathrm{~s})^{0}$ configurations lying higher in energy by 0.372 and $0.242 \mathrm{eV}$, respectively. Previously, both triplet- $\mathrm{C}_{2 v}[20,24,26]$ and quintet- $\mathrm{C}_{6 v}[21-23,25,27,28]$ states have been theoretically predicted as possible ground states. However, a quintet- $\mathrm{C}_{6 v}$ ground state was predicted only by the B3LYP method, and previous studies on the reaction products formed between group 5 transition metals $(\mathrm{V}, \mathrm{Nb}, \mathrm{Ta})$ and benzene revealed the B3LYP method to calculate the correct ground state only for the $\mathrm{C}_{6} \mathrm{H}_{6}-\mathrm{Nb}$ complex [29]. It was already suggested that triplet- $\mathrm{C}_{2 v}$ is the real ground state of the $\mathrm{C}_{6} \mathrm{H}_{6}$-Ti complex [26] at DFTPBW91 level of theory, and our OLYP evidence leads us to agree with such suggestions. Conclusive evidence from experimental data on the ground state of the $\mathrm{C}_{6} \mathrm{H}_{6}-\mathrm{Ti}$ complex is, however, still lacking.

As a consequence of the Jahn-Teller distortion, the planar $\mathrm{C}_{6 v} \mathrm{C}_{6} \mathrm{H}_{6}$ structure undergoes a deformation, characterized by a ruffling of the $\mathrm{C}_{6}$ ring (up or down displacement of the $\mathrm{C}$ atoms along the $z$-axis), Figure 1. Also, an elongation of all the $\mathrm{C}-\mathrm{C}$ bonds in the $\mathrm{C}_{6} \mathrm{H}_{6}$ - $\mathrm{Ti}$ compound of up to $4 \%$ is observed, because of the charge donation from the $\mathrm{C}_{6} \mathrm{H}_{6}$ bonding $\mathrm{e}_{1}$ states to the metal atom. The $\mathrm{C}_{6 v}$ planar configuration may distort in two different ways towards a $\mathrm{C}_{2 v}$ configuration, one characterized by a displacement along the $z$-axis of two para carbon atoms towards Ti, labeled as $[4+$ 2 ], the other one by displacement of the other four carbon atoms towards $\mathrm{Ti}$, labeled as $[2+4]$ configuration. In both cases, the distance along the $z$-axis between the $\mathrm{Ti}$ and the displaced $\mathrm{C}$ atoms is reduced from the $\mathrm{C}_{6 v}$ value of $1.66 \AA$ to 1.56 and $1.59 \AA$ values of the $[2+4]$ and $[4+2] \mathrm{C}_{2 v}$ configurations, respectively. Energies reported in Figure 2 are relative to the $\mathrm{C}_{6 v}$ structure with planar $\mathrm{C}_{6} \mathrm{H}_{6}$.

Figure 3 shows the electronic structure of the $\mathrm{C}_{6} \mathrm{H}_{6} \mathrm{Ti}$ $\left(\mathrm{C}_{2 v}-[2+4]\right)$ complex. The Jahn-Teller distortion from the planar $C_{6 v}$ to the $[2+4]$ distorted $C_{2 v}$ structures causes 


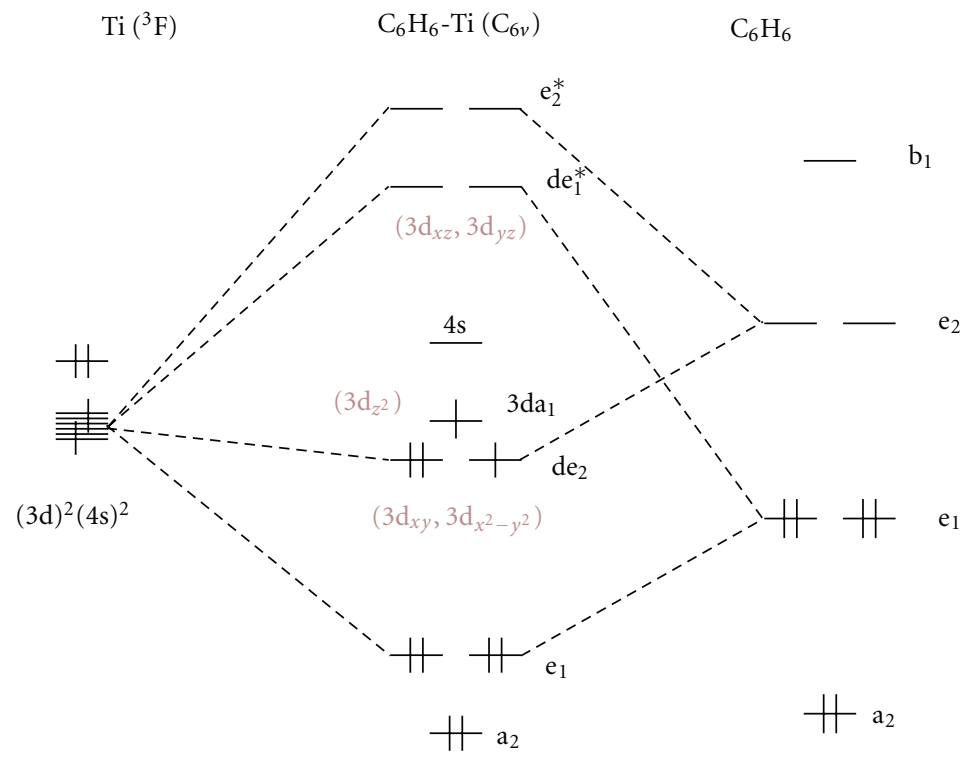

FIgURE 1: Orbital interaction diagram of the $\mathrm{C}_{6} \mathrm{H}_{6} \mathrm{Ti}-\mathrm{C}_{6 v}$ configuration.

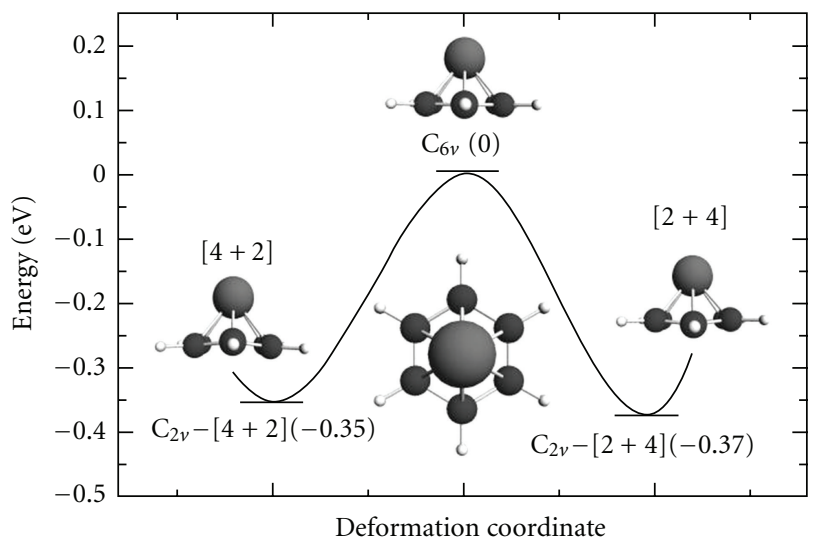

Figure 2: Energy diagram at DFT-OLYP level of the calculated $\mathrm{C}_{6} \mathrm{H}_{6}$-Ti triplet configurations. The smooth line is a pure schematic guide between the three configurations. Hydrogen, carbon, and titanium atoms are shown in white, dark grey, and light grey, respectively.

a splitting of the degenerate $\mathrm{C}_{6} \mathrm{H}_{6} \mathrm{Ti}$ de 2 levels (Figure 1) into the $8 a_{1}$ and $3 a_{2}$ states as shown in Figure 3. These now lie lower in energy than the Ti- $3 \mathrm{~d}_{z^{2}}$ (he $9 \mathrm{a}_{1}$ in Figure 3 ) with $3 \mathrm{da}_{1}$ (Figure 1) parentage. In the corresponding $[2+$ 4] configuration of the benzene, the $e_{2}$ LUMO splits into an $\mathrm{a}_{2}$ and an $\mathrm{a}_{1}$ orbital, which stabilize the $8 \mathrm{a}_{1}\left(\mathrm{Ti}-3 \mathrm{~d}_{x^{2}-y^{2}}\right.$ ) and $3 \mathrm{a}_{2}\left(\mathrm{Ti}-3 \mathrm{~d}_{x y}\right)$ MOs by admixing in a bonding fashion. The $x$-axis is perpendicular to the direction of the $2 \mathrm{C}$ atoms of the $[2+4]$ structure (and again the $2 \mathrm{C}$ atoms of the [4 $+2]$ structure). The triplet $\mathrm{C}_{2 v}-[2+4]$ configuration is thus characterized by a doubly occupied $8 \mathrm{a}_{1}-\mathrm{Ti}-3 \mathrm{~d}_{x^{2}-y^{2}}$ state and singly occupied $9 \mathrm{a}_{1}-\mathrm{Ti}-3 \mathrm{~d}_{z^{2}}$ and $3 \mathrm{a}_{2}-\mathrm{Ti}-3 \mathrm{~d}_{x y}$ states. In the alternative $\mathrm{C}_{2 v}-[4+2]$ Jahn-Teller configuration, the splitting of the $\mathrm{e}_{2}$ is reversed, the $3 \mathrm{a}_{2}-\mathrm{Ti}-3 \mathrm{~d}_{x y}$ state lies lower in energy, while the Ti- $3 \mathrm{~d}_{x^{2}-y^{2}}$ lies in higher position. Thus, the electron configuration in the distorted $[4+2]$ geometry is characterized by a doubly occupied $3 \mathrm{a}_{2}-\mathrm{Ti}-3 \mathrm{~d}_{x y}$ state of the metal atom and a singly occupied Ti- $3 \mathrm{~d}_{x^{2}-y^{2}}$. However, in both configurations, the $3 d_{z^{2}}$ state is singly occupied ( $9 a_{1}$ state in both [2+4] and [4+2] configurations). In all cases the empty Ti-4s $\left(10 \mathrm{a}_{1}\right)$ is present, which potentially could act as acceptor orbital for electrons from the approaching $\mathrm{H}_{2}$.

3.2. $\mathrm{H}_{2}$ Dissociative Adsorption on $\mathrm{C}_{6} \mathrm{H}_{6}-\mathrm{Ti}$. Taking the triplet $\mathrm{C}_{2 v}-[2+4]$ as the representative electronic ground state of the $\mathrm{C}_{6} \mathrm{H}_{6}$-Ti compound, we now turn to investigate the role played by the Ti addition in the adsorption of the four $\mathrm{H}_{2}$ molecules on the $\mathrm{C}_{6} \mathrm{H}_{6}$-Ti compound reported by Yildirim and Ciraci [10]. The first $\mathrm{H}_{2}$ addition proved to lead to dissociation of the corresponding hydrogen molecule, while an additional three molecules could be weakly bonded to the $\mathrm{Ti}$ atom on the SWNT surface. We therefore obtain here, for the $\mathrm{C}_{6} \mathrm{H}_{6}$ - $\mathrm{Ti}$ compound, the same $\mathrm{H}_{2}$ adsorption pattern observed in the $(8,0)$ Ti-SWNT studied in Reference [10].

Figure 4 shows the total energies of the $\mathrm{C}_{6} \mathrm{H}_{6} \mathrm{TiH}_{2}$ complex as a function of the distance between the metal atom and the center of mass of the approaching $\mathrm{H}_{2}$. All energies are relative to the value of the triplet curve at large distance, that is, the chosen energy zero is the sum of the energies of isolated ground state $\mathrm{H}_{2}$ and ground state triplet $\mathrm{C}_{6} \mathrm{H}_{6} \mathrm{Ti}[2+$ 4]. For each value of the constrained $\mathrm{Ti}-\mathrm{H}_{2}$ distance a full geometry optimization was carried out in both triplet and singlet states by relaxing to equilibrium all unconstrained degrees of freedom. The $\mathrm{H}_{2}$ approach turns out to be with the center of mass on the $z$-axis and the $\mathrm{H}_{2}$ bond axis perpendicular to the $z$-axis and in the direction of the two equivalent $\mathrm{C}$ atoms of the $[2+4]$ configuration, which is the $x$-axis. Similar to the $\mathrm{H}_{2}$ adsorption on a SWNT [10] we find the $\mathrm{C}_{6} \mathrm{H}_{6} \mathrm{Ti}-\mathrm{H}_{2}$ complex to be in a triplet ground state at large $\mathrm{Ti}-\mathrm{H}_{2}$ distances and to undergo a transition to the singlet at $1.72 \AA$. At variance with the barrierless dissociative adsorption of $\mathrm{H}_{2}$ on the $(8,0)$ Ti-SWNT studied in Reference 


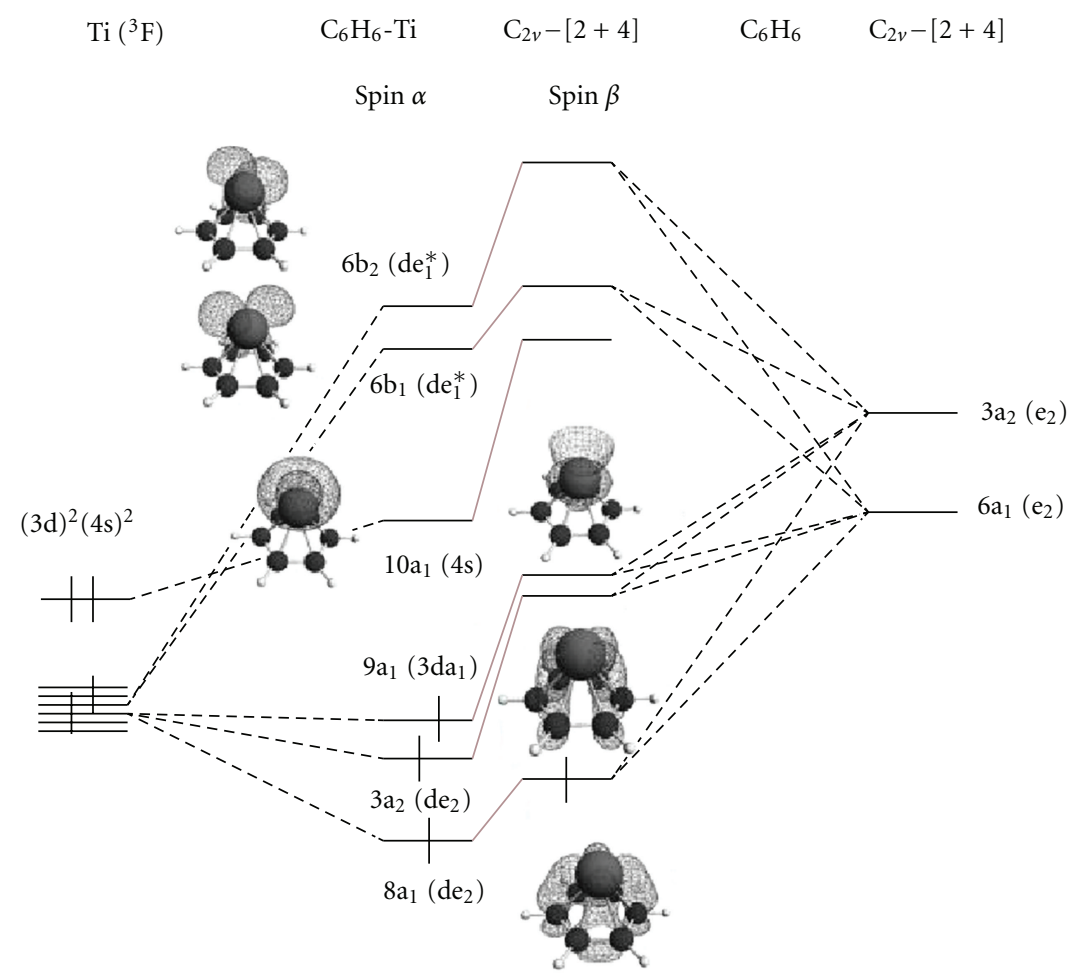

FIgURE 3: MO interaction diagram of the formation of $\mathrm{C}_{6} \mathrm{H}_{6} \mathrm{Ti}_{2 v}-[2+4]$ from $\mathrm{Ti}$ and $\mathrm{C}_{6} \mathrm{H}_{6}$. In parentheses the parentage of the levels from those of $\mathrm{C}_{6 v} \mathrm{C}_{6} \mathrm{H}_{6} \mathrm{Ti}$ (with planar $\mathrm{C}_{6} \mathrm{H}_{6}$ ), see Figure 1 . Hydrogen, carbon, and titanium atoms are shown in white, dark grey, and light grey, respectively.

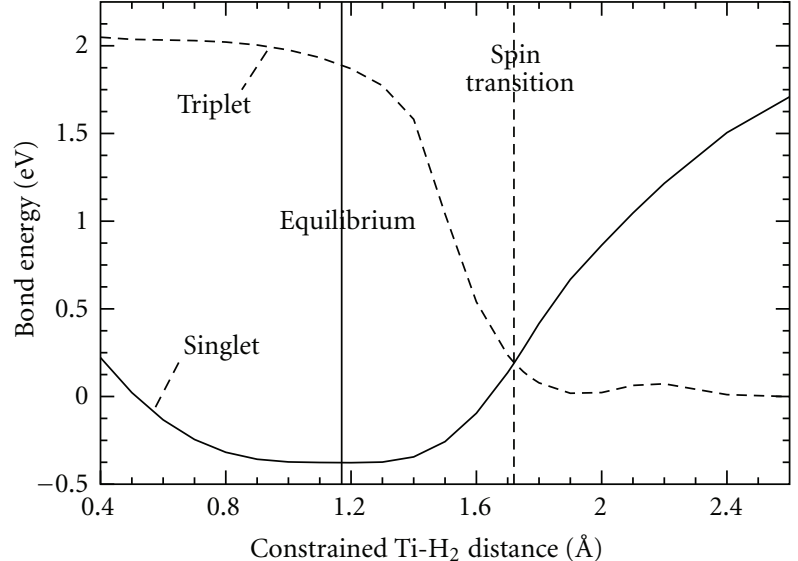

Figure 4: Total energies of the $\mathrm{C}_{6} \mathrm{H}_{6} \mathrm{Ti}[2+4]-\mathrm{H}_{2}$ complex for different constrained $\mathrm{Ti}-\mathrm{H}_{2}$ distances, measured from $\mathrm{Ti}$ to the center of mass of $\mathrm{H}_{2} \cdot \mathrm{H}_{2}$ approaches perpendicular to the $z$-axis, lying along the $x$-axis (in the direction of the $2 \mathrm{C}$ atoms of the $[2+$ 4] structure). The triplet and singlet states (dashed and straight line, resp.) are compared. Vertical lines indicate the equilibrium distance of $1.12 \AA$ (straight line) and the transition point at $1.72 \AA$ (dashed line). All energies are relative to the value of the triplet curve at large distance we indicated as zero.

[10], a finite barrier $(0.17 \mathrm{eV})$ is computed here for the $\mathrm{H}_{2}$ addition to $\mathrm{C}_{6} \mathrm{H}_{6} \mathrm{Ti}$, given by the difference between the energy at the spin transition and the energy at the minimum of the triplet spin surface. The absence of a barrier for $\mathrm{H}_{2}$ dissociation in the $(8,0)$ Ti-SWNT is likely to arise from a selective stabilization of the singlet state relative to the triplet in the Ti-SWNT compared to $\mathrm{C}_{6} \mathrm{H}_{6} \mathrm{Ti}$. In Figure 4 this would result in the singlet curve joining smoothly the triplet one at Ti- $\mathrm{H}_{2}$ distances lower than $\sim 2 \AA$.

The $\mathrm{H}_{2}$ lowest unoccupied orbital (LUMO) $1 \sigma_{u}$ has $\mathrm{B}_{1}$ symmetry in $\mathrm{C}_{2 v}$, so it cannot mix with the de $\mathrm{e}_{2}$ orbitals $\left(8 \mathrm{a}_{1}\right.$ and $3 a_{2}$ in Figure 3 ) or with the $3 d_{z^{2}}$ or $4 s$ (both $A_{1}$ ), but it mixes very strongly with the $\mathrm{e}_{1}^{*}$-derived Ti- $3 \mathrm{~d}_{x z}$ (the $6 \mathrm{~b}_{1}$ of the $\mathrm{C}_{6} \mathrm{H}_{6} \mathrm{Ti}$ fragment). This orbital is a typical frontier orbital which is hybridized with the $4 \mathrm{p}_{x}$ and thereby acquires a large amplitude towards the incoming $\mathrm{H}_{2}$. The strong interaction of $1 \sigma_{u}$ and $3 \mathrm{~d}_{x z}$ results in a low-lying stabilized strongly mixed $\mathrm{C}_{6} \mathrm{H}_{6} \mathrm{TiH}_{2}-6 \mathrm{~b}_{1}$ level (Tables 1 and 2 and Figure 5). As the $\mathrm{H}_{2}$ molecule approaches the $\mathrm{C}_{6} \mathrm{H}_{6}$ Ti compound, this level stabilizes so much that it becomes successively occupied with two (spin-paired) electrons, which may be pictured as coming from the originally singly occupied $9 a_{1} \alpha$ and next $3 \mathrm{a}_{2} \alpha$ of $\mathrm{C}_{6} \mathrm{H}_{6} \mathrm{Ti}[2+4]$ of Figure 3 . This is a typical example of a bond-breaking reaction, where the initially empty strongly $\mathrm{H}-\mathrm{H}$-antibonding orbital becomes occupied. The stabilization of the $1 \sigma_{u}$ which makes the mixing with $3 \mathrm{~d}_{x z}$ very strong is of course concomitant with the stretching of the $\mathrm{H}_{2}$ molecule (the bond breaking). The whole process only requires a very low barrier of $0.17 \mathrm{eV}$.

The interaction of $\mathrm{H}_{2}$ with a transition metal is often weak, because occupied metal orbitals have Pauli repulsion 
$\mathrm{C}_{6} \mathrm{H}_{6} \mathrm{Ti} \quad \mathrm{C}_{2 v}-[2+4] \quad \mathrm{C}_{6} \mathrm{H}_{6} \mathrm{TiH}_{2} \quad \mathrm{C}_{2 v}-[2+4] \quad$ Dissociated $\mathrm{H}_{2}$

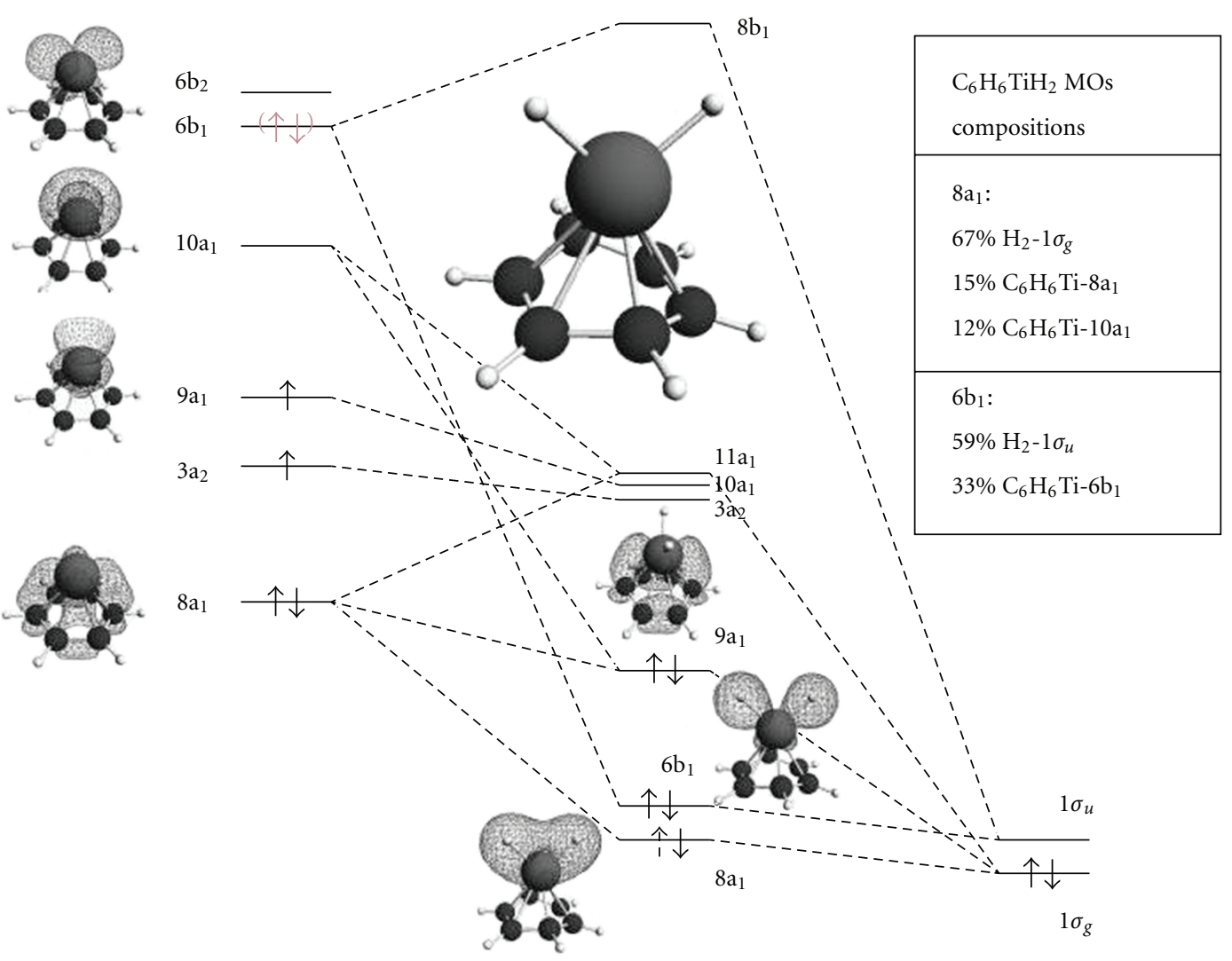

Figure 5: MO diagram for the $\mathrm{C}_{6} \mathrm{H}_{6}$ Ti- $\mathrm{H}_{2}$ dissociative interaction. Hydrogen, carbon, and titanium atoms are shown in white, dark grey, and light grey, respectively.

Table 1: $\mathrm{C}_{6} \mathrm{H}_{6} \mathrm{TiH}_{2}$ MOs energies (eV). Orbital labels refer to Figure 5.

\begin{tabular}{lccc}
\hline & \multicolumn{3}{c}{$\mathrm{d}\left(\mathrm{Ti}-\mathrm{H}_{2}\right)(\AA)$} \\
& $2.2(\uparrow / \downarrow)$ & $1.72(\uparrow \downarrow)$ & $1.17(\uparrow \downarrow)$ \\
\hline $\mathrm{C}_{6} \mathrm{H}_{6} \mathrm{TiH}_{2}-6 \mathrm{~b}_{1}$ & $-2.71 /-1.55$ & -3.85 & -5.64 \\
$\mathrm{C}_{6} \mathrm{H}_{6} \mathrm{TiH}_{2}-8 \mathrm{a}_{1}$ & $-11.50 /-11.28$ & -6.53 & -5.94 \\
\hline
\end{tabular}

TABle 2: $\mathrm{C}_{6} \mathrm{H}_{6} \mathrm{TiH}_{2}$ MOs composition (\%). Orbital labels refer to Figure 5.

\begin{tabular}{ccccc}
\hline & & \multicolumn{3}{c}{$\mathrm{d}\left(\mathrm{Ti}-\mathrm{H}_{2}\right)(\AA)$} \\
& & $2.2(\uparrow / \downarrow)$ & $1.72(\uparrow \downarrow)$ & $1.17(\uparrow \downarrow)$ \\
\hline $\mathrm{C}_{6} \mathrm{H}_{6} \mathrm{TiH}_{2}-6 \mathrm{~b}_{1}$ & $1 \sigma_{u}$ & $22 / 44$ & 48 & 59 \\
& $6 \mathrm{~b}_{1}-3 \mathrm{~d}_{x z}$ & $55 / 42$ & 41 & 33 \\
& $1 \sigma_{g}$ & $89 / 91$ & 74 & 67 \\
$\mathrm{C}_{6} \mathrm{H}_{6} \mathrm{TiH}_{2}-8 \mathrm{a}_{1}$ & $10_{1}-4 \mathrm{~s}$ & $3 / 3$ & 8 & 12 \\
& $9 \mathrm{a}_{1}-3 \mathrm{~d}_{z^{2}}$ & $1 / 1$ & 8 & \\
& $8 \mathrm{a}_{1}-3 \mathrm{~d}_{x^{2}-y^{2}}$ & & & 15
\end{tabular}

with the occupied $1 \sigma_{g}$ orbital of $\mathrm{H}_{2}$, preventing $\mathrm{H}_{2}$ from coming so close that the interaction of a metal $\mathrm{d}$ orbital with the $\mathrm{H}_{2} \quad 1 \sigma_{u}$ orbital can become strong. Typically another occupied metal d orbital then interacts only weakly with the high-lying $\mathrm{H}_{2} 1 \sigma_{u}$, resulting in weak backdonation. In the present case the coordinatively unsaturated $\mathrm{Ti}$ atom, with relatively few d electrons (as an early transition metal in the $3 \mathrm{~d}$ series), offers a route to strong interaction and $\mathrm{H}_{2}$ bond breaking. The $1 \sigma_{g}$ mixes (allowed by symmetry) with the $4 \mathrm{~s}$ and the $3 d_{z^{2}}$ states $\left(9 a_{1}\right.$ and $10 a_{1}$ of the $\mathrm{C}_{6} \mathrm{H}_{6}$ Ti fragment) but not with the $3 \mathrm{~d}_{x^{2}-y^{2}}\left(8 \mathrm{a}_{1}\right)$, see Table 2 . The antibonding combination of $3 \mathrm{~d}_{z^{2}}$ and $1 \sigma_{g}$, embodying the Paul repulsion, is destabilized in the process and loses its electron to the downwards moving $6 b_{1}$. The loss of the electron from the antibonding orbital implies disappearance of the Pauli repulsion, and the $\mathrm{H}_{2}$ can approach unhindered to optimize the interaction of $1 \sigma_{u}$ with $3 \mathrm{~d}_{x z}$ in the now fully occupied $6 b_{1}$, which leads to the bond breaking. At the same time, there is a low-lying bonding combination of the (mostly) $1 \sigma_{g}$ orbital with the $\mathrm{Ti}-3 \mathrm{~d}_{z^{2}}$, resulting in the orbital $8 \mathrm{a}_{1}$, which remains fully occupied (with the original two electrons of $\left.1 \sigma_{g}\right)$. This orbital is further stabilized by favorable mixing with the $\mathrm{Ti} 4 \mathrm{~s}\left(10 \mathrm{a}_{1}\right)$ and the $\mathrm{Ti}-3 \mathrm{~d}_{x^{2}-y^{2}}$ (note the percentages of $12 \%$ and $15 \%$, resp. in the $8 \mathrm{a}_{1}$, Table 2 ). This contributes to the force pulling $\mathrm{H}_{2}$ to Ti. So ultimately the two electrons 
of $\mathrm{H}_{2}$ end up in the Ti- $1 \sigma_{g}\left(\mathrm{H}_{2}\right)$ bonding orbital $8 \mathrm{a}_{1}$ and out of the four Ti electrons two go into the Ti- $1 \sigma_{u}\left(\mathrm{H}_{2}\right)$ bonding orbital $6 \mathrm{~b}_{1}(\mathrm{H}-\mathrm{H}$ bond breaking), while the two remaining ones reside in the largely nonbonding Ti-3 $\mathrm{d}_{x^{2}-y^{2}}\left(9 \mathrm{a}_{1}\right)$. The final resulting electron configuration has only doubly occupied orbitals, that is, it is a singlet state. The transition from the triplet to the singlet state occurs at a distance of $1.72 \AA$ between the Ti atom and the incoming $\mathrm{H}_{2}$ molecule.

Figure 5 shows the orbital interactions between the $\mathrm{C}_{6} \mathrm{H}_{6} \mathrm{Ti}$ complex and the adsorbed $\mathrm{H}_{2}$ molecule in the singlet equilibrium geometry. For analysis the systems was divided into two fragments: the $\mathrm{C}_{6} \mathrm{H}_{6} \mathrm{Ti} \mathrm{C}_{2 v}-[2+4]$ complex described before and the hydrogen molecule with the $\mathrm{H}-$ $\mathrm{H}$ distance lengthened to the dissociated value (2.61 $\AA$ ). At such a long $\mathrm{H}-\mathrm{H}$ distance the $1 \sigma_{g}\left(\mathrm{~A}_{1}\right.$ symmetry in $\left.\mathrm{C}_{2 v}\right)$ and $1 \sigma_{u}$ ( $\mathrm{B}_{1}$ symmetry) orbitals have little bonding/antibonding character left and are almost degenerate. As described above, these two $\mathrm{H}_{2}$-based orbitals enter the orbital energy diagram as the states $8 a_{1}$ and $6 b_{1}$, below the $3 d$ orbitals, with a good deal of mixing of these $\mathrm{H}_{2}$ orbitals and the metal orbitals. The internal caption in the figure shows the composition of the $\mathrm{C}_{6} \mathrm{H}_{6} \mathrm{TiH}_{2} \mathrm{C}_{2 v}-[2+4] 8 \mathrm{a}_{1}$ and $6 \mathrm{~b}_{1}$ MOs.

3.3. Adsorption of Two and Four $\mathrm{H}_{2}$ Molecules. Turning now to the addition of two $\mathrm{H}_{2}$ molecules, we observe that Figure 6 shows two adsorption patterns, one in which one of the $\mathrm{H}_{2}$ molecules is dissociated (Figure 6(a)) and one in which purely molecular adsorptions are observed (Figure 6(b)). In the dissociative configuration (a) the distance between the centers of mass of the first and the second $\mathrm{H}_{2}$ molecule and the $\mathrm{Ti}$ is predicted to be 0.76 and $1.81 \AA$, respectively, with a lengthened $0.84 \AA$ bond for the second nondissociated molecule and a $\mathrm{H}-\mathrm{H}$ distance of $3.22 \AA$ for the dissociated one. The $\mathrm{H}-\mathrm{H}$ distance in a free $\mathrm{H}_{2}$ molecule is $0.74 \AA$. In the configuration (b), the two $\mathrm{H}_{2}$ molecules were added in a position other than the on-top adsorption site of the $\mathrm{Ti}$. The optimized geometry predicted a displacement between the center of mass of the two $\mathrm{H}_{2}$ molecules and the Ti atom of $0.98 \AA$ and $1.77 \AA$ along the $z$-axis and the $x y$-plane, respectively. The adsorbed $\mathrm{H}_{2}$ bond length was calculated to be $0.78 \AA$. The first configuration is energetically favored by $0.38 \mathrm{eV}$ over the second.

Table 3 shows the composition of the MOs involved in the donation/backdonation bonding mechanisms. In the configuration (a), the system was divided again in two fragments: $\mathrm{C}_{6} \mathrm{H}_{6} \mathrm{TiH}_{2}$ and the second undissociated $\mathrm{H}_{2}$ molecule. In the configuration (b), the system was divided into a $\mathrm{C}_{6} \mathrm{H}_{6} \mathrm{Ti}$ and two $\mathrm{H}_{2}$ fragments. In both configurations, the added $\mathrm{H}_{2}$ molecules bind weakly to the Ti and do not dissociate with bonding energies of 0.10 and $0.20 \mathrm{eV}$ per $\mathrm{H}_{2}$ molecule, respectively.

In the configuration (a), the dissociation of the second $\mathrm{H}_{2}$ molecule is hindered by the double occupancy of the $\mathrm{C}_{6} \mathrm{H}_{6} \mathrm{TiH}_{2}-8 \mathrm{a}_{1}$ orbital, which prevents the second $\mathrm{H}_{2}$ molecule from approaching the adsorption site by the Pauli repulsion (occupied-occupied orbital repulsion of $1 \sigma_{g}$ with $\left.8 \mathrm{a}_{1}\right)$. Strong mixing of the high-lying $\mathrm{H}_{2} \quad 1 \sigma_{u}$ with a suitable occupied metal fragment orbital is therefore blocked, and
TABle 3: Compositions of the MOs involved in the $\mathrm{H}_{2}$ donation/backdonation bonding mechanism for the adsorption of two $\mathrm{H}_{2}$ molecules on the $\mathrm{C}_{6} \mathrm{H}_{6}$ Ti complex.

\begin{tabular}{lc}
\hline $\mathrm{C}_{6} \mathrm{H}_{6} \mathrm{TiH}_{2}-\mathrm{H}_{2}$ & $\mathrm{C}_{6} \mathrm{H}_{6} \mathrm{Ti}-2 \mathrm{H}_{2}$ \\
$6 \mathrm{a}_{1}$ & $3 \mathrm{~b}_{1}$ \\
\hline $83 \% \mathrm{H}_{2}-1 \sigma_{g}$ & $91 \% \mathrm{H}_{2}-1 \sigma_{g}(\mathrm{x} 2)$ \\
$7 \% \mathrm{C}_{6} \mathrm{H}_{6} \mathrm{TiH}_{2}-10 \mathrm{a}_{1}$ & $6 \% \mathrm{C}_{6} \mathrm{H}_{6} \mathrm{Ti}-6 \mathrm{~b}_{1}$ \\
\hline $6 \mathrm{~b}_{1}$ & $6 \mathrm{a}_{1}$ \\
\hline $87 \% \mathrm{C}_{6} \mathrm{H}_{6} \mathrm{TiH}_{2}-6 \mathrm{~b}_{1}$ & $85 \% \mathrm{H}_{2}-1 \sigma_{g}(\mathrm{x} 2)$ \\
$10 \% \mathrm{H}_{2}-1 \sigma_{u}$ & $4 \% \mathrm{C}_{6} \mathrm{H}_{6} \mathrm{Ti}-6 \mathrm{a}_{1}$ \\
\hline & $3 \mathrm{~b}_{2}$ \\
\hline & $88 \% \mathrm{C}_{6} \mathrm{H}_{6} \mathrm{Ti}-3 \mathrm{a}_{2}$ \\
& $10 \% \mathrm{H}_{2}-1 \sigma_{u}(\mathrm{x} 2)$ \\
\hline
\end{tabular}

significant stabilizing mixing between the $1 \sigma_{g}$ and the empty $10 \mathrm{a}_{1}-3 \mathrm{~d}_{z^{2}}$ and the $11 \mathrm{a}_{1}-4 \mathrm{~s}$ is also prevented. Charge donation from the $\mathrm{C}_{6} \mathrm{H}_{6} \mathrm{Ti}$ complex to the $1 \sigma_{u}$ of the second $\mathrm{H}_{2}$ molecule is thus avoided, (which could take place in the first dissociative $\mathrm{H}_{2}$ addition and caused the $\mathrm{H}-\mathrm{H}$ bond breaking). The empty $10 \mathrm{a}_{1}$ and $11 \mathrm{a}_{1}$ orbitals, with large $3 \mathrm{~d}_{z^{2}}$ and $4 \mathrm{~s}$ character, do act to some extent as acceptor orbitals (cf. the $7 \% 10 \mathrm{a}_{1}$ mixing with the $1 \sigma_{g}$ in Table 3 ), but bond breaking would require the antibonding $1 \sigma_{u}$ orbital to be filled.

In the configuration (b), the dissociation of the two $\mathrm{H}_{2}$ molecules does not occur since the orbital overlaps between the $\mathrm{C}_{6} \mathrm{H}_{6} \mathrm{Ti}$ and $\mathrm{H}_{2}$ remain too weak in this configuration. For instance, the calculated overlap between $9 \mathrm{a}_{1}$ and $1 \sigma_{g}$ was 0.114 , while a 0.765 value was obtained for the $\mathrm{C}_{6} \mathrm{H}_{6} \mathrm{Ti}-\mathrm{H}_{2}$ dissociative adsorption described before. The two $\mathrm{H}_{2}$ molecules should approach the $\mathrm{C}_{6} \mathrm{H}_{6}$ Ti fragment more closely in order to build better overlaps but would then experience substantial repulsion. The first dissociation in configuration (a) occurs because the antibonding $\mathrm{H}_{2}$ orbital $1 \sigma_{u}$ gets filled through its strong interaction with the exposed $\mathrm{Ti}-3 \mathrm{~d}_{x z}$. In general, dissociation requires that electrons are dumped into the antibonding (bond-breaking) orbital. This does not occur in configuration (b) because of the repulsion between $\mathrm{C}_{6} \mathrm{H}_{6} \mathrm{Ti}-8 \mathrm{a}_{1}$ and $1 \sigma_{g}$ 's. In addition, bond breaking requires occupation of the $1 \sigma_{u}$ orbitals. In the depicted configuration the $1 \sigma_{u}$ orbitals cannot, however, establish strong interactions with unoccupied $\mathrm{C}_{6} \mathrm{H}_{6} \mathrm{TiH}_{2}$ orbitals and gain sufficient stabilization to bring about its occupation through the mechanism described above. A weak donation/backdonation mechanism is therefore responsible for the bonding between the $\mathrm{Ti}$ atom and the two $\mathrm{H}_{2}$ molecules also in this second configuration. Note that the $\mathrm{C}_{6} \mathrm{H}_{6} \mathrm{Ti}-6 \mathrm{~b}_{1}, 6 \mathrm{a}_{1}$ and $3 \mathrm{a}_{2}$ states indicated in the right panel of Table 3 consist mainly of the Ti- $3 \mathrm{~d}_{x z}$, a lower lying $\mathrm{C}_{6} \mathrm{H}_{6}$ $\mathrm{e}_{1}$ and the $\mathrm{Ti}-3 \mathrm{~d}_{x y} / \mathrm{C}-\mathrm{p}_{z}$ states, respectively.

We next consider the adsorption of four $\mathrm{H}_{2}$ molecules on the $\mathrm{C}_{6} \mathrm{H}_{6} \mathrm{Ti}$ complex. In this case, two stable four- $\mathrm{H}_{2}$ adsorption patterns were computed (Figure 7). We denote these two different configurations as $\mathrm{TiH}_{2}+3 \mathrm{H}_{2}$ (Figure $7(\mathrm{a})$ ) and $\mathrm{Ti}+4 \mathrm{H}_{2}$ (Figure $\left.7(\mathrm{~b})\right)$. These equilibrium structures are clearly related to the corresponding geometries in the two- $\mathrm{H}_{2}$ addition patterns (Figure 6). In both cases, no more than one 


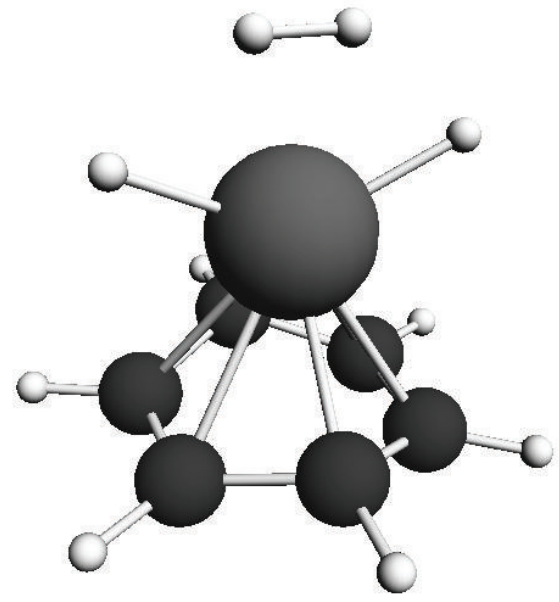

(a)

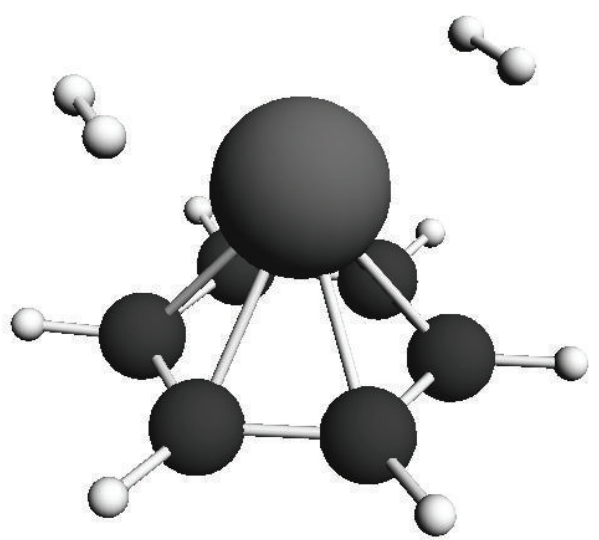

(b)

Figure 6: Adsorption patterns of two $\mathrm{H}_{2}$ molecules addition: (a) $\mathrm{C}_{6} \mathrm{H}_{6} \mathrm{Ti} \mathrm{H}_{2}-\mathrm{H}_{2}$, (b) $\mathrm{C}_{6} \mathrm{H}_{6} \mathrm{Ti}-2 \mathrm{H}_{2}$. Hydrogen, carbon, and titanium atoms are shown in white, dark grey, and light grey, respectively.

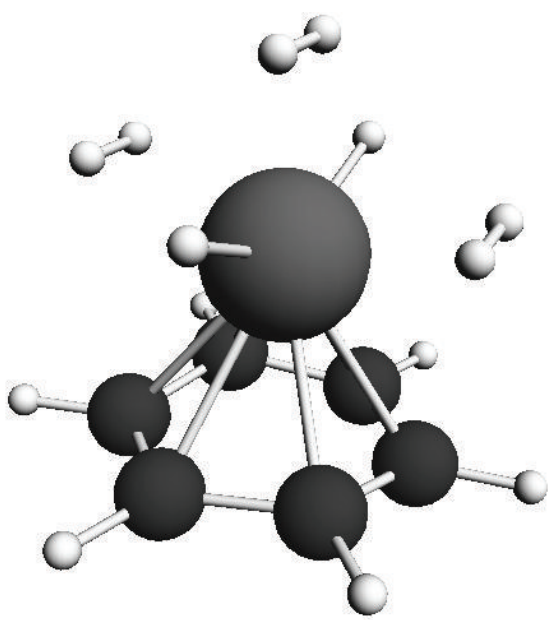

(a)

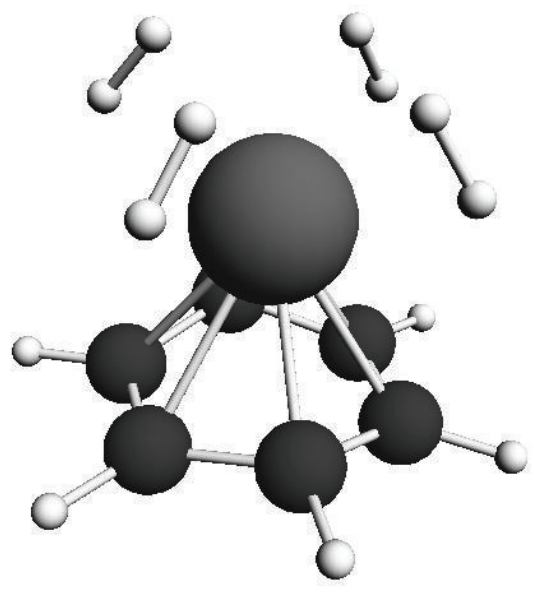

(b)

Figure 7: The two most stable four- $\mathrm{H}_{2}$ addition patterns: (a) $\mathrm{TiH}_{2}+3 \mathrm{H}_{2}$ and (b) $\mathrm{Ti}+4 \mathrm{H}_{2}$. Hydrogen, carbon, and titanium atoms are shown in white, dark grey, and light grey, respectively.

$\mathrm{H}_{2}$ molecule undergoes dissociative adsorption, and when dissociation occurs an additional undissociated molecule resides on top of the adsorption site. In the configurations of type (b), the on-top site is left vacant. Similar configurations were found to be stable when using SWNT support in place of $\mathrm{C}_{6} \mathrm{H}_{6}$ for the Ti catalyst [10]. The final optimized $\mathrm{TiH}_{2}$ $+3 \mathrm{H}_{2}$ structure is $0.32 \mathrm{eV}$ lower than $\mathrm{Ti}+4 \mathrm{H}_{2}$. In the very symmetric $\mathrm{Ti}+4 \mathrm{H}_{2}$ configuration, all the four molecules stay intact, with an average $\mathrm{H}-\mathrm{H}$ bond distance and bond energy of $0.82 \AA$ and $0.23 \mathrm{eV}$, respectively.

Table 4 shows a comparison between the benzene and SWNT supports. It is important to notice that the results presented in this paper agree with the hypothesis of Yildirim and Ciraci [10] about the characteristic properties of a $\mathrm{Ti}$ atom supported by a hexagonal-carbon-based framework and its hydrogen adsorption properties. Also, our orbital analysis substantiates the picture of the $\mathrm{Ti}-\mathrm{C}-\mathrm{H}_{2}$ interaction proposed by the authors for the SWNT support. There are nonetheless important differences between the two supports. In the first instance the adsorption energy of the first dissociative $\mathrm{H}_{2}$ addition is much reduced in the benzene support (from $0.83 \mathrm{eV}$ to $0.37 \mathrm{eV}$ ). In addition, the dissociative addition is an activated process which suggests, according to the argument of Section 3.1, that the singlet state is stabilized in the SWNT compared to the benzene support. Furthermore, when four molecules are adsorbed, in the benzene-Ti system, one is dissociated, the others are not. In the SWNT none is dissociated. The very symmetric SWNT-Ti- $4 \mathrm{H}_{2}$ configuration was found to lie lower in energy by $0.10 \mathrm{eV}$ than the SWNT- $\mathrm{TiH}_{2} 3 \mathrm{H}_{2}$ [10]. It may therefore be argued that the yield of molecular $\mathrm{H}_{2}$ adsorption in the $\mathrm{C}_{6} \mathrm{H}_{6}$ - Ti system would be lower than in the SWNT (one need to recombine 
TABLE 4: Comparison of SWNT and $\mathrm{C}_{6} \mathrm{H}_{6}$ supports for $\mathrm{H}_{2}$ adsorption on Ti.

\begin{tabular}{lcc}
\hline Support & $\mathrm{C}_{6} \mathrm{H}_{6}$ & SWNT [10] \\
\hline preferred configuration & $\mathrm{TiH}_{2}+3 \mathrm{H}_{2}$ & $\mathrm{Ti}+4 \mathrm{H}_{2}$ \\
adsorption energy per $\mathrm{H}_{2}$ molecule & $0.23 \mathrm{eV}$ & $0.54 \mathrm{eV}$ \\
first dissociative $\mathrm{H}_{2}$ addition energy & $0.37 \mathrm{eV}$ & $0.83 \mathrm{eV}$ \\
$\mathrm{Ti}+4 \mathrm{H}_{2}: \mathrm{H}-\mathrm{H}$ distance & $0.82 \AA$ & $0.84 \AA$ \\
\hline
\end{tabular}

one molecule when releasing hydrogen). Finally, the average Ti- $\mathrm{H}_{2}$ adsorption energy decreases from $0.54 \mathrm{eV}$ for the SWNT support to $0.23 \mathrm{eV}$ for the $\mathrm{C}_{6} \mathrm{H}_{6}$. In conclusion, although the $\mathrm{C}_{6} \mathrm{H}_{6}$ support for the Ti addition qualitatively reproduces the dominant local contribution of the large gap $(8,0)$ SWNT, the different boundary conditions of the two materials, finite system in the case of $\mathrm{C}_{6} \mathrm{H}_{6}$, infinite periodic in the case of the SWNT, lead to sizable differences in the adsorption energies. The result is a favored $\mathrm{Ti}+4 \mathrm{H}_{2}$ configuration for the periodic SWNT support of the Ti atom and the more localized $\mathrm{TiH}_{2}+3 \mathrm{H}_{2}$ as the favored pattern for $\mathrm{C}_{6} \mathrm{H}_{6}$. We stress that, in the $\mathrm{TiH}_{2}+3 \mathrm{H}_{2}$ configuration, the first $\mathrm{H}_{2}$ adsorption is dissociative, while the other three are not. From a material modelling viewpoint, the $\mathrm{C}_{6} \mathrm{H}_{6}$-Ti complex can be seen as an "almost converged" model system for the SWNT$\mathrm{Ti}$ with respect to cluster size. Nevertheless, $\mathrm{C}_{6} \mathrm{H}_{6}-\mathrm{Ti}$ can store the same number of $\mathrm{H}_{2}$ molecules per Ti atom, achieving a $6 \%$ weight percentage of stored hydrogen. Indeed, some electronic relationship between SWNT and $\mathrm{C}_{6} \mathrm{H}_{6}$ may be expected from the modern theory of the macroscopic polarization [30]. According to such theory, the quadratic spread of the manybody electronic wavefunction in condensed phase has an upper bound, in the presence of a finite gap $E_{g}$ :

$$
\lambda<\frac{\hbar^{2}}{2 m E_{g}},
$$

where $\lambda$ is the so called localization length [30], defined by a unitary operator based on a Berry phase in place of the position operator, and $m$ is the electron mass. Qualitatively, (1) can be read as "the larger the gap, the more localized the electrons are". Indeed, $(8,0)$ SWNT is a large gap insulator nanotube, thus limiting the quadratic spread of the manybody electronic wavefunction. This means that, as normal for insulators, the interaction between $\mathrm{Ti}$ adatom and the SWNT may be expected to consist of a dominant local contribution from the $\mathrm{C}_{6}$ hexagon surrounding the metal atom. When we isolate the carbon hexagon support of the $\mathrm{Ti}$ atom, the $\mathrm{C}_{6} \mathrm{H}_{6}$ is obtained by hydrogen passivation of the dangling bonds. Benzene can be therefore provide the simplest model system in which the local effects occurring in the large gap insulator $(8,0)$ SWNT may be represented.

\section{Summary and Conclusions}

We studied the adsorption of one, two, and four $\mathrm{H}_{2}$ molecules on a single titanium atom supported on a benzene molecule. In all cases we found one $\mathrm{H}_{2}$ molecule to adsorb dissociatively and the remaining one(s) to bind to the metal ion center through weak-charge transfer interaction. The dissociative addition was found to involve a transition from the triplet to the singlet energy surface, similar to what has been found in the adsorption of $\mathrm{H}_{2}$ on a titanium atom supported on a $(8,0)$ SWNT. At variance with the latter, this was, however, found to be an activated process, with a barrier of $0.17 \mathrm{eV}$. The Ti- $\mathrm{H}_{2}$-binding energy was estimated to be $\sim 0.4 \mathrm{eV}$ lower than in the SWNT. The main emphasis of this work has been on a detailed analysis of the orbital interactions responsible for the $\mathrm{H}_{2}$ binding to $\mathrm{Ti}$ and for the dissociation of one $\mathrm{H}_{2}$ molecule. Typically, the coordination of $\mathrm{H}_{2}$ to a transition metal atom (or ion) is very weak, because the occupied $1 \sigma_{g}$ orbital will have Pauli repulsion with occupied metal orbitals. This prevents $\mathrm{H}_{2}$ from coming close and interacting strongly by way of its high-lying $1 \sigma_{u}$, which could lead to breaking of the $\mathrm{H}-\mathrm{H}$ bond. In the Tibenzene system, however, the situation is different due to the small number of $\mathrm{d}$ electrons and due to fact that the interaction with the benzene "prepares" the Ti $3 \mathrm{~d}$ orbitals for the interaction with $\mathrm{H}_{2}$. Notably, the Pauli repulsion, which is embodied in the antibonding interaction of the occupied $1 \sigma_{g}$ of $\mathrm{H}_{2}$ with an occupied mostly $3 \mathrm{~d}_{z^{2}}$ orbital, is relieved by the loss of the two electrons from the rising antibonding combination of the $1 \sigma_{g}$ and $3 \mathrm{~d}_{z^{2}}$. These electrons are transferred to an in-phase (bonding) combination of the (originally empty) Ti $3 \mathrm{~d}_{x z}$ and $\mathrm{H}_{2} 1 \sigma_{u}$ orbitals, which comes down due to the stabilizing interaction. We also find that the empty $\mathrm{Ti}$ 4s orbital can interact favorably with $\mathrm{H}_{2}$, which adds to the force pulling the $\mathrm{H}_{2}$ in. In essence, $\mathrm{Ti}$ is specially favorable because the combination of the small number of four d electrons and the special orbital interactions with benzene lead to just the right electronic structure for easy dissociation of $\mathrm{H}_{2}$. Our results elucidate the electronic structure reasons for the high potential of $\mathrm{Ti}$ on carbon supports as new and efficient materials for hydrogen storage.

\section{Acknowledgments}

This work was supported by the Netherlands Organization for Scientific Research through the ACTS Programme for Sustainable Hydrogen. Computer resources were provided by the Netherlands' Scientific Research Council (NWO) through a grant from Stichting Nationale Computerfaciliteiten (NCF). Support was also given by the WCU (World Class University) program through the Korea Science and Engineering Foundation funded by the Ministry of Education, Science and Technology of the Republic of Korea (Project no. R32-2008-000-10180-0).

\section{References}

[1] R. Coontz and B. Hanson, "Not so simple," Science, vol. 305, no. 5686, p. 957, 2004.

[2] A. Züttel, P. Wenger, P. Sudan, P. Mauron, and S.-I. Orimo, "Hydrogen density in nanostructured carbon, metals and complex materials," Materials Science and Engineering B, vol. 108, pp. 9-18, 2004. 
[3] M. Felderhoff, C. Weidenthaler, R. Von Helmolt, and U. Eberle, "Hydrogen storage: the remaining scientific and technological challenges," Physical Chemistry Chemical Physics, vol. 9, no. 21, pp. 2643-2653, 2007.

[4] S. A. Shevlin and Z. X. Guo, "High-capacity room-temperature hydrogen storage in carbon nanotubes via defect-modulated titanium doping," Journal of Physical Chemistry C, vol. 112, no. 44, pp. 17456-17464, 2008.

[5] A. Bhattacharya, S. Bhattacharya, C. Majumder, and G. P. Das, "Transition-metal decoration enhanced room-temperature hydrogen storage in a defect-modulated graphene sheet," Journal of Physical Chemistry C, vol. 114, no. 22, pp. 10297-10301, 2010.

[6] H. Lee, M. C. Nguyen, and J. Ihm, "Titanium-functional group complexes for high-capacity hydrogen storage materials," Solid State Communications, vol. 146, no. 9-10, pp. 431434, 2008.

[7] Y. Liu, L. Ren, Y. He, and H.-P. Cheng, “Titanium-decorated graphene for high-capacity hydrogen storage studied by density functional simulations," Journal of Physics Condensed Matter, vol. 22, no. 44, Article ID 445301, 2010.

[8] A. B. Phillips, B. S. Shivaram, and G. R. Mynenib, "Hydrogen absorption at room temperature in nanoscale titanium benzene complexes," International Journal of Hydrogen Energy, vol. 37, no. 2, pp. 1546-1550, 2011.

[9] P. F. Weck, T. J. D. Kumar, E. Kim, and N. Balakrishnan, "Computational study of hydrogen storage in organometallic compounds," Journal of Chemical Physics, vol. 126, no. 9, Article ID 094703, 2007.

[10] T. Yildirim and S. Ciraci, "Titanium-decorated carbon nanotubes as a potential high-capacity hydrogen storage medium," Physical Review Letters, vol. 94, no. 17, Article ID 175501, 2005.

[11] F. M. Bickelhaupt and E. J. Baerends, "Kohn-Sham density functional theory: predicting and understanding chemistry," Reviews in Computational Chemistry, vol. 15, pp. 1-86, 2000.

[12] ADF2005.01, SCM, Theoretical Chemistry, Vrije Universiteit Amsterdam, The Netherlands, http://www.scm.com/.

[13] E. J. Baerends, D. E. Ellis, and P. Ros, "Self-consistent molecular Hartree-Fock-Slater calculations I. The computational procedure," Chemical Physics, vol. 2, no. 1, pp. 41-51, 1973.

[14] C. Fonseca Guerra, J. G. Snijders, G. Te Velde, and E. J. Baerends, "Towards an order-N DFT method," Theoretical Chemistry Accounts, vol. 99, no. 6, pp. 391-403, 1998.

[15] N. C. Handy and A. J. Cohen, "Left-right correlation energy," Molecular Physics, vol. 99, pp. 403-412, 2001.

[16] C. Lee, W. Yang, and R. G. Parr, "Development of the ColleSalvetti conelation energy formula into a functional of the electron density," Physical Review B, vol. 37, no. 2, pp. 785789, 1988.

[17] M. Swart, A. R. Groenhof, A. W. Ehlers, and K. Lammertsma, "Validation of exchange-correlation functional for spin states of iron complexes," Journal of Physical Chemistry A, vol. 108, no. 25, pp. 5479-5483, 2004.

[18] A. J. C. W. M. Hoe and N. C. Handy, "Assessment of a new local exchange functional OPTX," Chemical Physics Letters, vol. 341, pp. 319-328, 2001.

[19] X. Xu and W. A. Goddard, "Assessment of Handy-Cohen optimized exchange density functional (OPTX)," Journal of Physical Chemistry A, vol. 108, no. 40, pp. 8495-8504, 2004.

[20] G. Hong, F. Schautz, and M. Dolg, "Ab initio study of metalring bonding in the bis $\left(\eta^{6}\right.$ - benzene $)$ lanthanide and -actinide complexes $\mathrm{M}\left(\mathrm{C}_{6} \mathrm{H}_{6}\right)_{2}(\mathrm{M}=\mathrm{La}, \mathrm{Ce}, \mathrm{Nd}, \mathrm{Gd}, \mathrm{Tb}, \mathrm{Lu}, \mathrm{Th}, \mathrm{U})$,"
Journal of the American Chemical Society, vol. 121, no. 7, pp. 1502-1512, 1999.

[21] R. Pandey, B. K. Rao, P. Jena, and M. A. Blanco, "Electronic structure and properties of transition metal-benzene complexes," Journal of the American Chemical Society, vol. 123, no. 16, pp. 3799-3808, 2001.

[22] R. Pandey, B. K. Rao, P. Jena, and M. A. Blanco, Journal of the American Chemical Society, vol. 123, p. 7744, 2001.

[23] T. Kurikawa, H. Takeda, M. Hirano et al., "Electronic properties of organometallic metal-benzene complexes [Mn (benzene)m ( $\mathrm{M}=\mathrm{Sc}-\mathrm{Cu})$ ]," Organometallics, vol. 18, no. 8, pp. 1430-1438, 1999.

[24] A. Ouhlal, A. Selmani, and A. Yelon, "Bonding in ( $\eta 6-\mathrm{C} 6 \mathrm{H} 6)$ $\mathrm{M}$ and ( $\eta 6-\mathrm{C} 6 \mathrm{H} 6) \mathrm{M}+, \mathrm{M} \mathrm{Ti}, \mathrm{Cr}, \mathrm{Ni}$, and $\mathrm{Cu}$. A local spin density study," Chemical Physics Letters, vol. 243, no. 3-4, pp. 269-274, 1995.

[25] P. Chaquin, D. Costa, C. Lepetit, and M. Che, "Structure and bonding in a series of neutral and cationic transition metalbenzene $\eta 6$ complexes $[\mathrm{M}(\eta 6-\mathrm{C} 6 \mathrm{H} 6)] \mathrm{n}+(\mathrm{M}=\mathrm{Ti}, \mathrm{V}, \mathrm{Cr}, \mathrm{Fe}$, $\mathrm{Co}, \mathrm{Ni}$, and $\mathrm{Cu}$ ). Correlation of charge transfer with the bathochromic shift of the E1 ring vibration," Journal of Physical Chemistry A, vol. 105, no. 18, pp. 4541-4545, 2001.

[26] J. T. Lyon and L. Andrews, "Group 4 transition metal-benzene adducts: carbon ring deformation upon complexation," Journal of Physical Chemistry A, vol. 110, no. 25, pp. 7806-7815, 2006.

[27] R. Pandey, B. K. Rao, P. Jena, and J. M. Newsam, "Unique magnetic signature of transition metal atoms supported on benzene," Chemical Physics Letters, vol. 321, no. 1-2, pp. 142$150,2000$.

[28] K. Imura, H. Ohoyama, and T. Kasai, "Metal-ligand interaction of Ti-C ${ }_{6} \mathrm{H}_{6}$ complex size-selected by a 2-m long electrostatic hexapole field," Chemical Physics Letters, vol. 369, no. 1-2, pp. 55-59, 2003.

[29] J. T. Lyon and L. Andrews, "V, Nb, and Ta complexes with benzene in solid argon: an infrared spectroscopic and density functional study," Journal of Physical Chemistry A, vol. 109, no. 3, pp. 431-440, 2005.

[30] R. Resta, "Why are insulators insulating and metals conducting?" Journal of Physics Condensed Matter, vol. 14, no. 20, pp. R625-R656, 2002. 

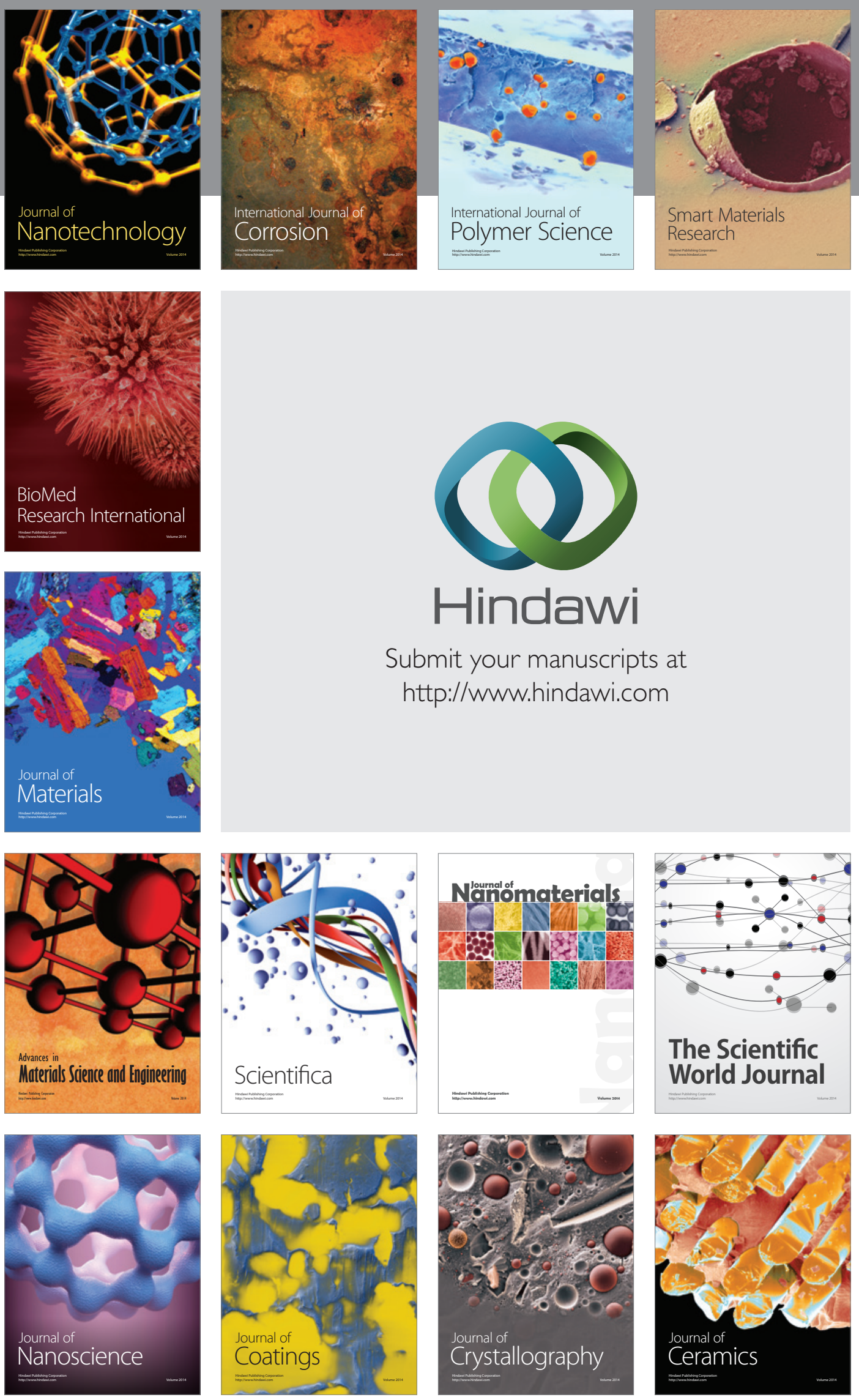

The Scientific World Journal

Submit your manuscripts at

http://www.hindawi.com

\section{World Journal}

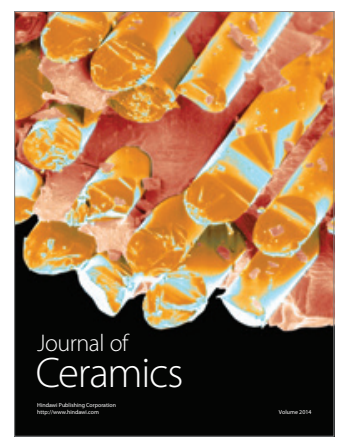

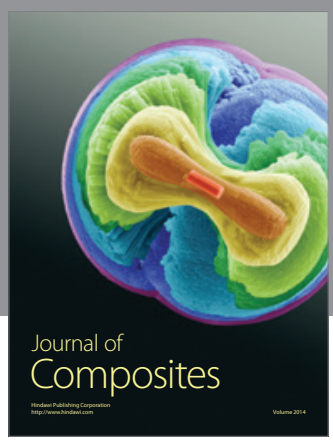
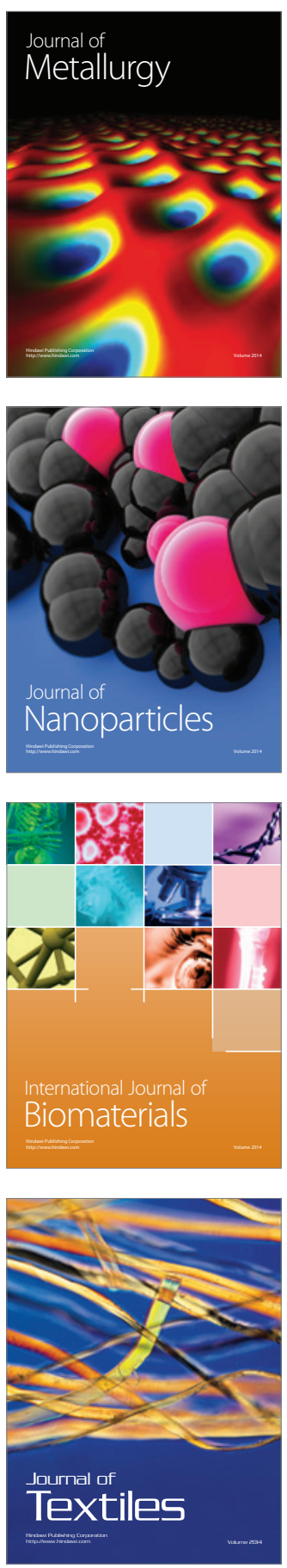